\title{
Simultaneous estimation of lidocaine and prilocaine in topical cream by green gas chromatography
}

\author{
Hashim Chekku Marakkarakath, Gurupadayya Bannimath*, Prachi Pramesh Raikar \\ Department of Pharmaceutical Chemistry, JSS College of Pharmacy, JSS Academy of Higher Education \& Research, Mysuru, India.
}

\begin{tabular}{l}
\hline ARTICLE INFO \\
\hline Received on: 04/11/2018 \\
Accepted on: 09/02/2019 \\
Available online: $30 / 03 / 2019$
\end{tabular}

\section{Key words:}

Gas chromatography,

ICH guidelines, lidocaine,

prilocaine, simultaneous

estimation.

\begin{abstract}
Lidocaine (LDC) and prilocaine (PLC) are estimated in a topical local anesthetic cream using a direct, eco-friendly, stability-indicating gas chromatographic technique with flame ionization detector. The mixture of LDC and PLC was separated using Zebron DB drug column. The column temperature and flow rate were $230^{\circ} \mathrm{C}$ and $14 \mathrm{ml} / \mathrm{minute}$, respectively. The retention time was found to be 5.1 minutes for PLC and 5.4 minutes for LDC. Linearity was observed in the concentration range of $20-100 \mu \mathrm{g} / \mathrm{ml}$ and $10-50 \mu \mathrm{g} / \mathrm{ml}$ for LDC and PLC, respectively. The method was validated and values of linearity, limit of detection, limit of quantification, precision, and accuracy were found to be in good accordance with the International Conference on Harmonization guideline. A direct, stability-indicating method was developed for the determination of LDC and PLC in topical dosage forms in the presence of its degradation products. The proposed method can be useful in the quality control of LDC and PLC in their topical formulation.
\end{abstract}

\section{INTRODUCTION}

Lidocaine (LDC) is a local anesthetic which acts by causing barricade of sodium channel that shows a decrease in sodium conductance and lowered rate of electrical depolarization, ultimately leading to blockade of conduction. Synthetically, LDC is 2-(diethylamino)-N-(2, 6-dimethylphenyl) acetamide (Powell and Hydrochloride, 1986). Prilocaine (PLC) is an amide local anesthetic with pharmacological properties like lignocaine. Synthetically, PLC is (RS)-N-(2-Methylphenyl)-2-(propylamino) propanamide. PLC, in contrast to other amide analgesics, is an optional amino subordinate of Toludine. It delivers less vasodilation and toxicity than $\mathrm{LDC}$ and is viewed as moderately free from an unfavorably susceptible response (Rishiraj et al., 2005; Warren et al., 1974). The structures of PLC and LDC are shown in Figure 1.

Many studies have been reported in the literature to determine PLC and LDC. A few spectrophotometric (Atila

\section{"Corresponding Author}

Gurupadayya B. M., Department of Pharmaceutical Chemistry, JSS College of Pharmacy, JSS Academy of Higher Education \& Research, Mysuru, India. E-mail: bmgurupadayya@jssuni.edu.in and Kadioglu, 2012; Karthikkumar et al., 2012; Rizk et al., 1997), chromatographic (Fijałek et al., 2005; Kadioglu and Atila, 2008; Klein et al., 1994; Liawruangrath et al., 2001; Malenovic et al., 2005; Mohammad, 2009; Pendela et al., 2011; Plenis et al., 2013; Ricci Júnior et al., 2002; Storms and Stewart, 2002; Wiberg and Jacobsson, 2004; Zylber-Katz et al., 1978), fluid chromatography-couple mass spectrometry (Dal Bo et al., 1999; Koehler et al., 2005; Ter Weijden et al., 2012), gas chromatography flame ionization detection (Baniceru et al., 2004; Culea et al., 1989; Keenaghan, 1968; Levine et al., 1983; Reynolds and Beckett, 1968), gas chromatographymass spectrometry (Kadioglu and Atila, 2007; Watanabe et al., 1998; Yang et al., 2009), capillary electrophoresis (Siluveru and Stewart, 1997), and high performance liquid chromatography (HPLC) methods were reported to determine PLC and LDC in both pharmaceutical formulations and human plasma.

Many studies have been reported to determine PLC and LDC in pharmaceutical preparation (Atila and Kadioglu, 2012; Dal Bo et al., 1999; Fijałek et al., 2005; Karthikkumar et al., 2012; Liawruangrath et al., 2001; Malenovic et al., 2005; Mohammad, 2009; Narendra and Shailesh, 2017; Pendela et al., 2011; Plenis et al., 2013; Ricci Júnior et al., 2002; Rizk et al., 1997; Wiberg and Jacobsson, 2004), human plasma (Dal Bo et al., 1999; 
<smiles>CCCNC(C)C(=O)Nc1ccccc1C</smiles>

(a) Prilocaine

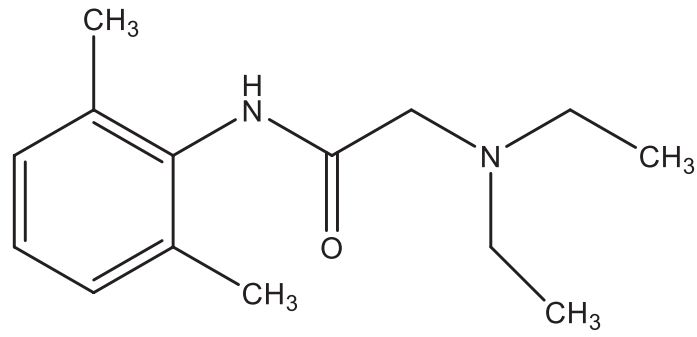

(b) Lidocaine

Figure 1. Chemical structures of (a) PLC and (b) LDC.

Kadioglu and Atila, 2007; 2008; Klein et al., 1994; Ter Weijden et al., 2012; Zylber-Katz et al., 1978), human serum (Koehler et al., 2005; Siluveru and Stewart, 1997), and in human blood (Watanabe et al., 1998).

To the best of our insight into the study of analytical chemistry, no such green analytical method was reported for estimation of PLC and LDC in a topical cream. Researchers developing green gas chromatography follow the 3 R's rule (Reduce, Replace, and Recycle). The focus of the present work is to develop and validate green gas chromatographic (GC) method for PLC and LDC in a topical formulation. We have developed some eco-friendly GC methods for several drugs with minimum use of solvents in our laboratory (Chandan et al., 2013; Gurupadayya et al., 2010; Indupriya et al., 2011; Soujanya et al., 2011; Thejaswini et al., 2012; Vijayakumar et al., 2016). The proposed technique was in accordance with the parameters of International Conference on Harmonization (ICH) guidelines, including linearity, limit of detection (LOD), limit of quantification (LOQ), accuracy, and precision (ICH, 2005).

\section{MATERIALS AND METHODS}

\section{Experimental}

\section{Instrument}

The instrument utilized in this investigation is the GC Shimadzu 2014 model associated with a flame ionization detector controlled by GC solution software. A sample applicator for $\mathrm{GC}$ was equipped with $1 \mu \mathrm{l}$ syringe (Hamilton Bonaduz $\mathrm{AG}$, Switzerland); the column utilized was Zebron DB drug column (Length: $30 \mathrm{~m}$, Diameter: $0.25 \mathrm{~mm}$ and Film: $0.50 \mu \mathrm{m}$ ) with a temperature range of -40 to 320 (Max. $340^{\circ} \mathrm{C}$ ).
Materials

Pure LDC and PLC were procured from Martin and Brown Bio-Sciences (Nalagarh), Himachal Pradesh, Mumbai, India. Marketable LDC (2.5\%) and PLC (2.5\%) topical local analgesic cream (PRILOX $30 \mathrm{~g}$ ) was obtained from a local pharmacy for the examination. HPLC grade 2-propanol was acquired from Merck specialities Pvt Ltd, Worli, Mumbai, India. Distilled water utilized in the trial was acquired from Milli-Q framework (Millipore). Millipore water is procured from Merck specialities Pvt. Ltd, Worli, Mumbai, India and $\mathrm{H}_{2} \mathrm{O}_{2}$ and other chemicals of analytical grade were procured from ACE Rasayan, Mysuru.

\section{ANALYTICAL PROCEDURES}

\section{Standard solutions}

By weighing $10 \mathrm{mg}$ of PLC and LDC into $10 \mathrm{ml}$ volumetric flask, standard stock solutions were prepared. Suitable dilutions of PLC and LDC were made using 2-propanol. The volume of injection was set to $1 \mu$ l. Calibration curve was plotted between peak area against the concentration for LDC and PLC independently. The linearity ranges were observed in the range of $20-100 \mu \mathrm{g} / \mathrm{ml}$ for LDC and $10-50 \mu \mathrm{g} / \mathrm{ml}$ PLC based on ICH guidelines.

\section{Analysis of marketed formulation}

To estimate the content of LDC and PLC in marketed topical formulation (LDC $2.5 \%$ and PLC $2.5 \%$ cream), the cream ( $1 \mathrm{~g}$ comparable to $25 \mathrm{mg}$ of both LDC and PLC) was weighed and extracted into $50 \mathrm{ml}$ 2-propanol with the aid of ultra-sonication for 15 minutes. On subsequent filtration into a $100 \mathrm{ml}$ volumetric flask by using syringe filter, the volume was made with 2-propanol to obtain a solution of $20 \mu \mathrm{g} / \mathrm{ml}$ for LDC and $10 \mu \mathrm{g} / \mathrm{ml}$ for PLC. Furthermore, dilution was made with 2-propanol from the above solution.

\section{Chromatographic conditions}

The mobile phase is comprised of nitrogen gas as carrier gas, hydrogen and zero air as supportive gases for the formation of flame in the flame ionization detector. The rate of flow was 14 $\mathrm{ml}$ per minute throughout the run. The temperature of the oven was adjusted at $210^{\circ} \mathrm{C}$ for 1 minute then increased to $280^{\circ} \mathrm{C}\left(5^{\circ} \mathrm{C} /\right.$ minute). The inlet temperature and detector temperature were $200^{\circ} \mathrm{C}$ and $280^{\circ} \mathrm{C}$, respectively. The injection volume and the split ratio were $1 \mu \mathrm{l}$ and 10:0, respectively, for determination of LDC and PLC in a topical formulation.

\section{Forced degradation studies}

Forced degradation studies were performed on formulations containing LDC and PLC in liquid states as indicated by the following conditions: $5 \mathrm{ml}$ of different fractions of LDC and PLC standard stock solutions were moved into $25 \mathrm{ml}$ volumetric flask and treated as expressed in Table 1. After the predetermined time, all the solutions, except that of photolytic degradation were left to cool. According to ICH guidelines, neutralization is done by adding the same amount and concentration of the alkaline solution to the acidic one and vice versa. The solutions of LDC and PLC were diluted to the required volume to obtain the final concentration of $200 \mu \mathrm{g} / \mathrm{ml}$. 
Table 1. PLC and LDC stress testing parameters.

\begin{tabular}{|c|c|c|c|c|}
\hline $\begin{array}{l}\text { Degradation } \\
\text { condition }\end{array}$ & $\begin{array}{l}\text { Concentration and } \\
\text { volume of reagent }\end{array}$ & Stress conditions & $\begin{array}{c}\text { Percentage of degradation } \\
\text { (PLC) }\end{array}$ & $\begin{array}{c}\text { Percentage of degradation } \\
\text { (LDC) }\end{array}$ \\
\hline \multicolumn{5}{|l|}{ Liquid state } \\
\hline Acid & $1 \mathrm{M}, \mathrm{HCl}(5 \mathrm{ml})$ & \multirow{4}{*}{ Water bath adjusted at $70^{\circ} \mathrm{C}$ for 30 minutes } & 25.1 & 22.8 \\
\hline Base & $1 \mathrm{M}, \mathrm{NaOH}(5 \mathrm{ml})$ & & 31.3 & 30.1 \\
\hline Neutral & Purified water $(5 \mathrm{ml})$ & & 18.7 & 28.5 \\
\hline Oxidation & $30 \% \mathrm{H}_{2} \mathrm{O}_{2}(5 \mathrm{ml})$ & & 28.8 & 22.2 \\
\hline Photolysis & Purified water $(5 \mathrm{ml})$ & $\begin{array}{l}\text { UV light at } 254 \text { and } 366 \mathrm{~nm} \text { at a separation of } \\
15 \mathrm{~cm} \text { from the light for } 4 \text { hours, revealed to } \\
\text { glow of a } 1.6 \text { million lux hours. }\end{array}$ & 57.2 & 68.7 \\
\hline
\end{tabular}

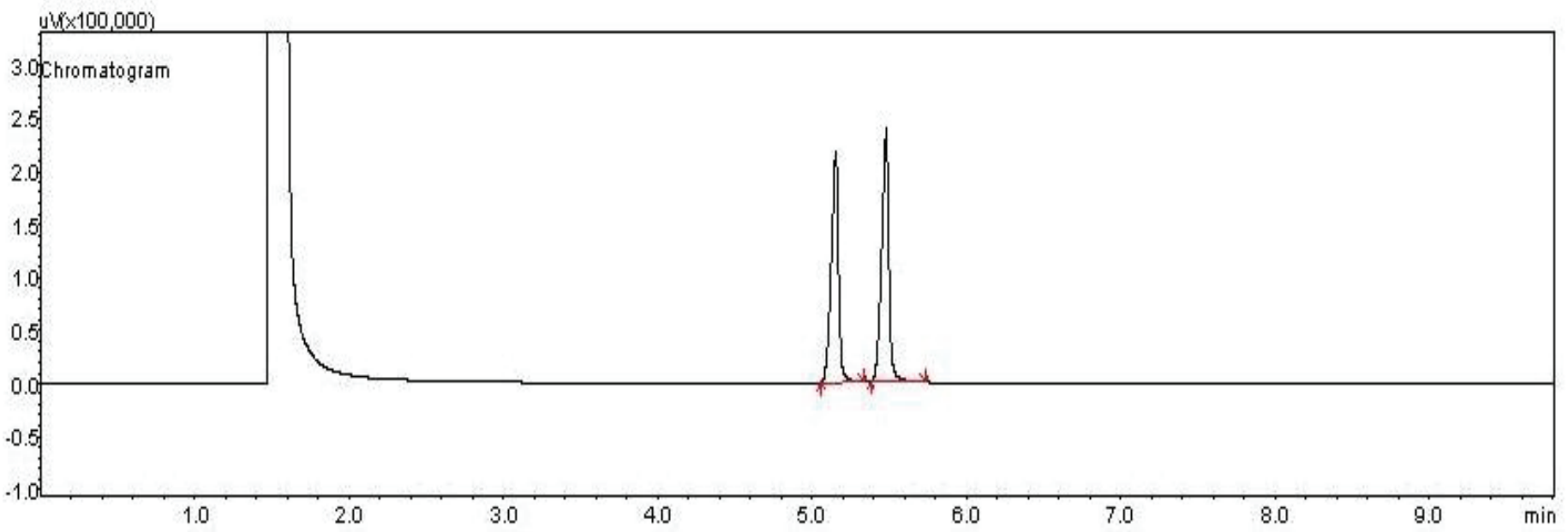

Figure 2. Chromatogram of PLC and LDC.

\section{RESULTS AND DISCUSSIONS}

\section{Optimization of procedures}

The GC methodology was used for simultaneous determination of LDC and PLC. The resolution of both drugs was more than 1.5 , obtained for the separation of two drugs using 2-propanol as a solvent. Therefore, 2-propanol was selected as an ideal solvent for the separation of two drugs. The stream rate of $14 \mathrm{ml} /$ minute was optimum. The retention times for LDC and PLC were observed to be 5.153 and 5.442 minutes, respectively, as depicted in Figure 2, and the overlay chromatogram of PLC and LDC was mentioned in Figure 3. The system suitability parameters for GC chromatogram are expressed in Table 2 (ICH, 2005). The comparison of the existing method parameters with reference HPLC method (Narendra and Shailesh, 2017) was highlighted in Table 3. Accordingly, the current method does not require any costly organic solvent during the process of method development.

\section{Method Validation}

\section{Linearity and range}

Calibration curves were plotted to determine the linearity over a concentration range of $10-50 \mu \mathrm{g} / \mathrm{ml}$ for PLC and $20-100 \mu \mathrm{g} / \mathrm{ml}$ for LDC. A $1 \mu \mathrm{l}$ of test solution was injected using septum injector. Chromatograms were noted. All measurements were repeated three times, by plotting a graph of relative drug concentration versus peak areas of component. The linear regression equations were $Y=$ $14,432 X-5,489.1\left(r^{2}=0.9972\right)$ for PLC and $Y=16,280 X-$ $15,697\left(r^{2}=0.9933\right)$ for LDC. The plots obtained from linear regression are given in Figure 4 for PLC and Figure 5 for LDC, respectively.

\section{Limits of detection and limit of quantitation}

The criteria used to ascertain LOD and LOQ are the 3.3 and $10 \sigma / \mathrm{s}$, individually.

Where $\sigma=$ standard deviation of the peak area.

$s=$ slope of the comparing calibration curve.

The values of LOD and the LOQ for PLC and LDC were mentioned in Table 4.

\section{Precision}

Three different samples were prepared at a concentration of low, medium, and high, and analysis was performed to determine the precision of the proposed method as intraday and interday precision. By analyzing standard drug solution within calibration range, both intraday precision, $\%$ relative standard deviation (\% RSD) (three times on the same day) and interday precision, \% RSD (three different days 


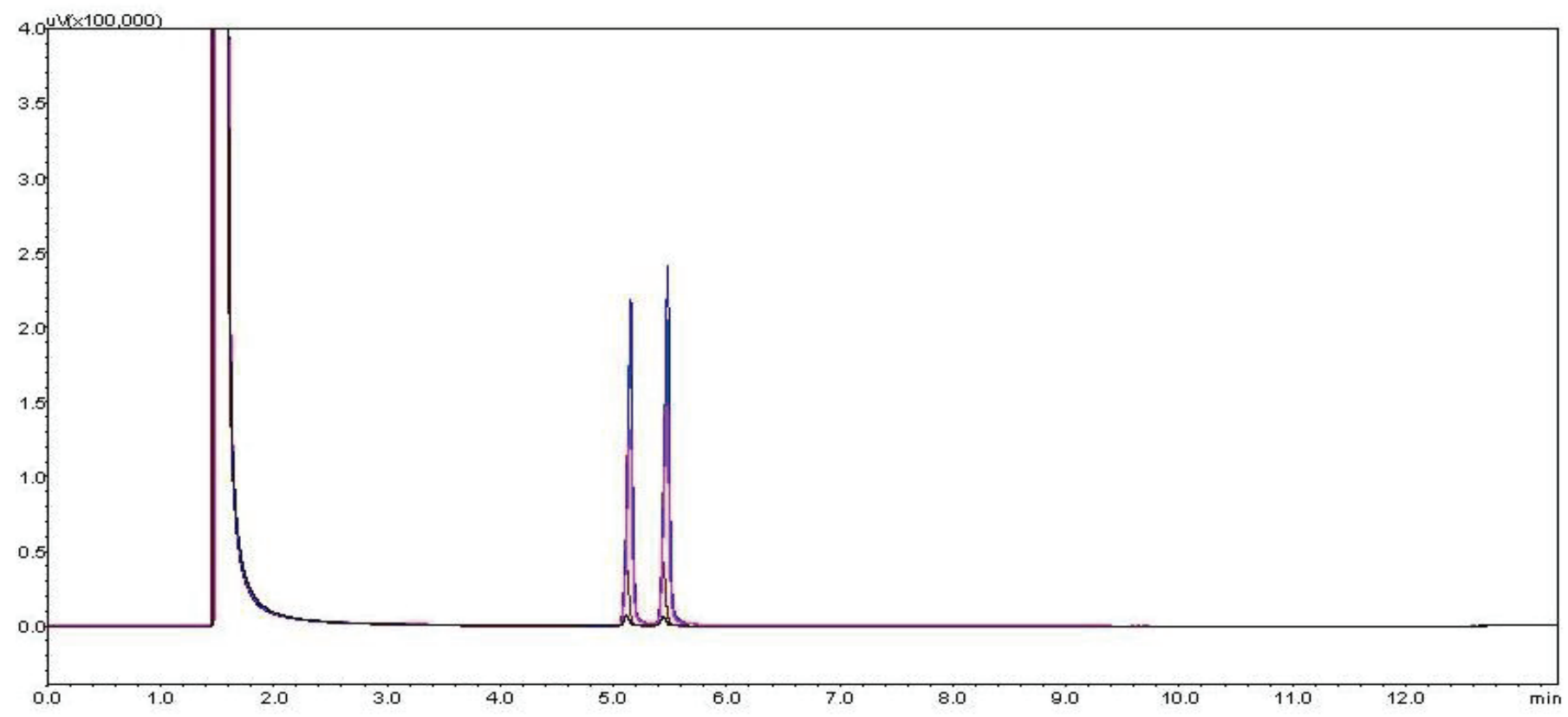

Figure 3. Overlay chromatogram of PLC and LDC.

Table 2. System suitability parameters of LDC and PLC.

\begin{tabular}{lccc}
\hline Parameters & PLC $(\boldsymbol{n}=\mathbf{6})$ & LDC $(\boldsymbol{n}=\mathbf{6})$ & Limits \\
\hline Retention time $\left(t_{R}\right)$ (minutes) & 5.13 & 5.45 & - \\
Resolution $(\mathrm{Rs})$ & - & 3.920 & $\geq 1.5$ \\
Theoretical plates $(N)$ & $59,883.03$ & $71,133.82$ & $N>2,000$ \\
Tailing factor $(T)$ & 0.963 & 1.003 & $T$ of $\leq 2$ \\
\hline
\end{tabular}

Table 3. Comparison of the reported method with the current method.

\begin{tabular}{llcccccc}
\hline Method & Drugs & Linearity $(\mu \mathrm{g} / \mathrm{ml})$ & LOD $(\boldsymbol{\mu g} / \mathbf{m l})$ & LOQ $(\mu \mathrm{g} / \mathrm{ml})$ & RSD & ${ }^{\mathrm{a}} \mathbf{R s}$ & ${ }^{\mathrm{b}} \boldsymbol{R}_{t}$ \\
\hline \multirow{2}{*}{ HPLC (Reference) } & LDC & $1-6$ & 0.3 & 0.8 & 99.70 & 7.06 & 8.64 \\
& PLC & $1-6$ & 0.2 & 0.6 & 99.77 & -- & 6.07 \\
\multirow{2}{*}{ Current method } & LDC & $20-100$ & 3.22 & 9.77 & 99.93 & 3.920 & 5.13 \\
& PLC & $10-50$ & 1.33 & 4.01 & 99.72 & --- & 5.4 \\
\hline
\end{tabular}

${ }^{\mathrm{a} R s:}$ resolution; ${ }^{\mathrm{b}} R_{t}$ : retention time.

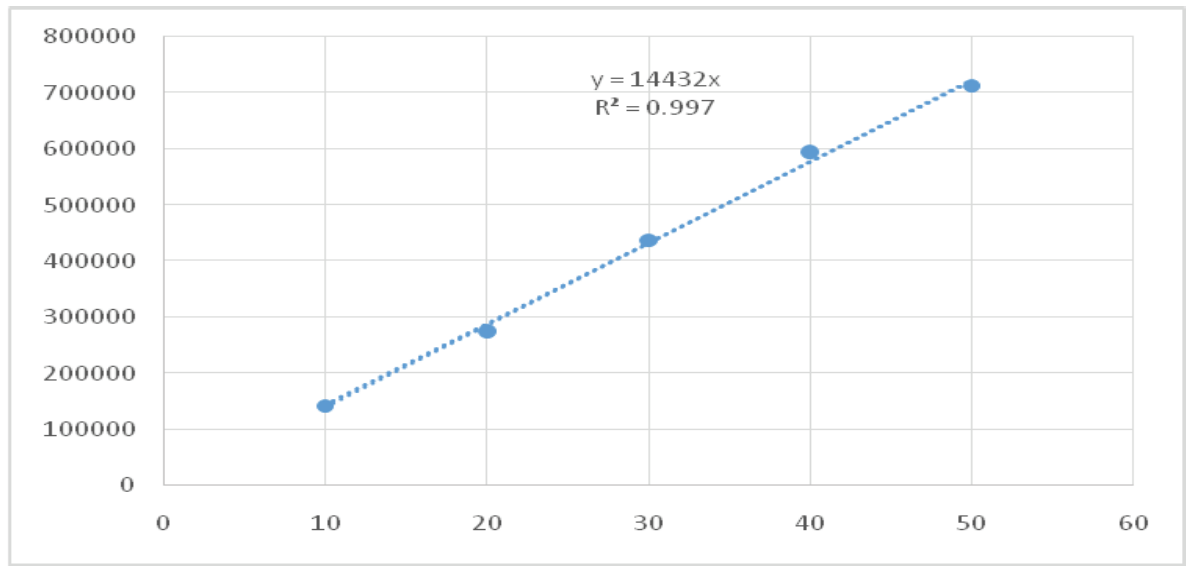

Figure 4. Calibration curve for PLC. 


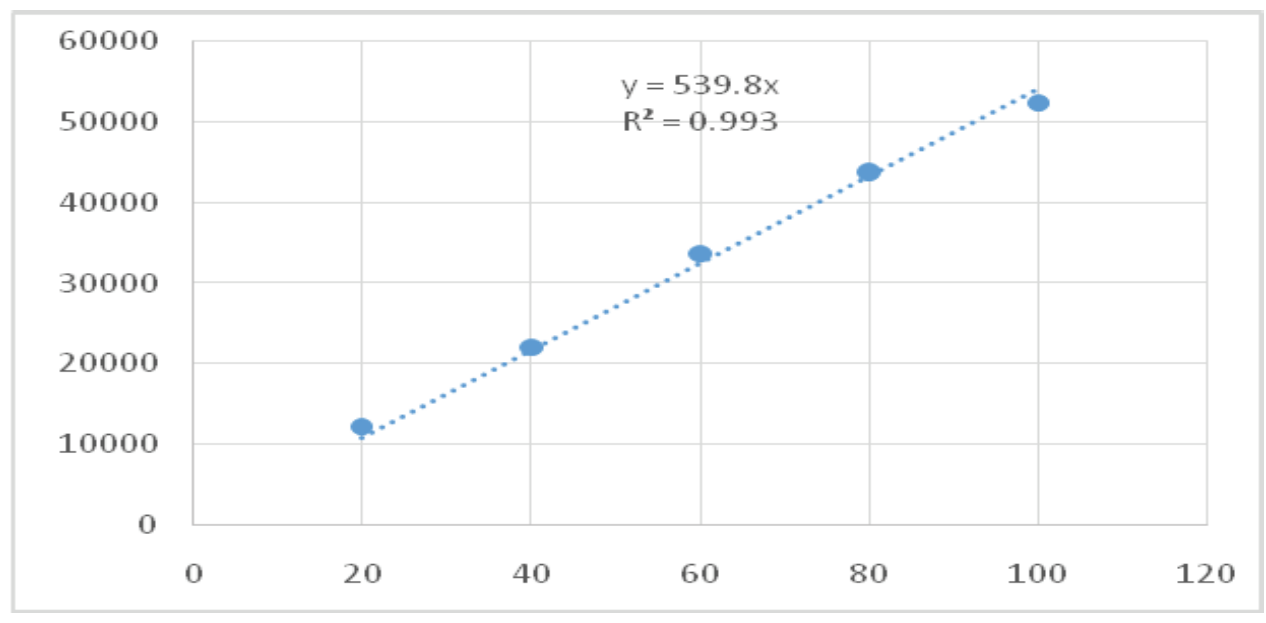

Figure 5. Calibration curve for LDC.

Table 4. LOD and LOQ for the proposed GC method.

\begin{tabular}{lcc}
\hline Drugs & LOD $(\boldsymbol{\mu g} / \mathbf{m l})$ & LOQ $(\mu \mathrm{g} / \mathrm{ml})$ \\
\hline LDC & 3.22 & 9.77 \\
PLC & 1.33 & 4.01 \\
\hline
\end{tabular}

Table 5. Intraday and interday precision study for the proposed GC method $(n=6)$.

\begin{tabular}{|c|c|c|c|c|c|c|c|}
\hline \multirow{2}{*}{ Drugs } & \multirow{2}{*}{$\begin{array}{c}\text { Concentration } \\
(\mu \mathrm{g} / \mathrm{ml})\end{array}$} & \multicolumn{3}{|c|}{ Intraday precision } & \multicolumn{3}{|c|}{ Interday precision } \\
\hline & & Peak area & $\%$ RSD & Mean $\%$ recovery \pm SD & Peak area & $\%$ RSD & Mean $\%$ recovery $\pm \mathrm{SD}$ \\
\hline \multirow{6}{*}{ PLC } & \multirow{6}{*}{30} & 419,543 & \multirow{6}{*}{1.0435} & \multirow{6}{*}{$99.66 \pm 108$} & 410,216 & \multirow{6}{*}{1.0614} & \multirow{6}{*}{$99.72 \pm 124$} \\
\hline & & 410,245 & & & 419,546 & & \\
\hline & & 419,568 & & & 410,213 & & \\
\hline & & 410,215 & & & 419,654 & & \\
\hline & & 419,452 & & & 419,546 & & \\
\hline & & 419,214 & & & 419,621 & & \\
\hline \multirow{6}{*}{ LDC } & \multirow{6}{*}{60} & 33,804 & \multirow{6}{*}{1.3484} & \multirow{6}{*}{$99.79 \pm 132$} & 33,415 & \multirow{6}{*}{1.6139} & \multirow{6}{*}{$99.93 \pm 145$} \\
\hline & & 34,333 & & & 34,954 & & \\
\hline & & 34,046 & & & 34,541 & & \\
\hline & & 34,548 & & & 34,015 & & \\
\hline & & 35,214 & & & 35,013 & & \\
\hline & & 34,015 & & & 34,215 & & \\
\hline
\end{tabular}

$\mathrm{RSD}<5 \%$.

over a period of a week) have been assessed. The precision of the method was expressed as RSD\%. The precision results shown in Table 5 were found within the limit and prove that the method was highly precise.

\section{Accuracy}

Accuracy in the analytical method is the difference between the theoretically added amount and practically achieved amount. Recovery studies were performed in triplicate by standard addition method at $80 \%, 100 \%$, and $120 \%$ to check the degree of accuracy of the method. A known amount of standard LDC and PLC were added to pre-analyzed samples, which were then exposed to the proposed method. Results of recovery study of GC method were shown in Table 6 , which were obtained in accordance with ICH guidelines.

\section{Forced degradation studies}

In the GC method, forced degradation was done on topical cream. The results showed that both PLC and LDC undergo degradation after subjecting the standard drug combination to the above stress condition with the appearance of specific retention time and peak area less than that of standard drug. GC chromatograms of LDC and PLC mixture degradation condition in acid, base, neutral, oxidation, and 
Table 6. Accuracy study for proposed GC $(n=3)$.

\begin{tabular}{lcccc}
\hline Label claim (per gram cream) & Amount added (\%) & Total amount $(\boldsymbol{\mu g} / \mathbf{m l})$ & \%Recovery & Mean \% recovery \pm SD \\
\hline \multirow{2}{*}{ PLC $(25 \mathrm{mg})$} & 80 & 30 & 99.55 & 98.98 \\
& 100 & 40 & 98.77 & $99.10 \pm 0.109$ \\
& 120 & 50 & 99.96 & $99.62 \pm 0.138$ \\
LDC $(25 \mathrm{mg})$ & 80 & 30 & 100.81 & 98.09 \\
\hline
\end{tabular}

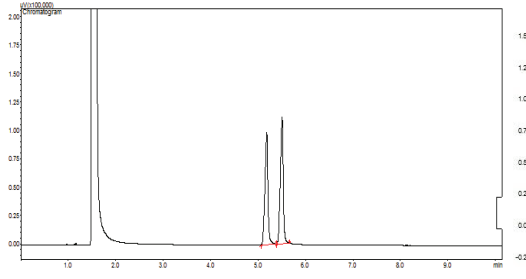

(a)

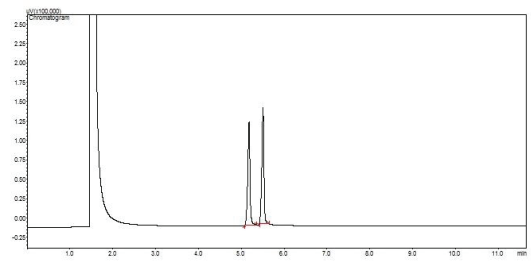

(c)

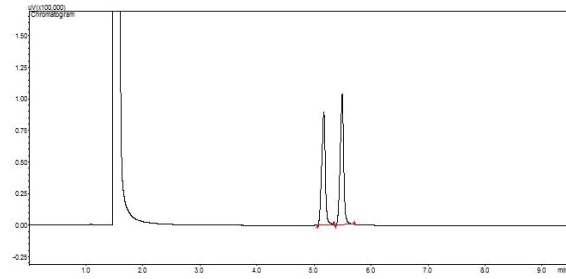

(b)

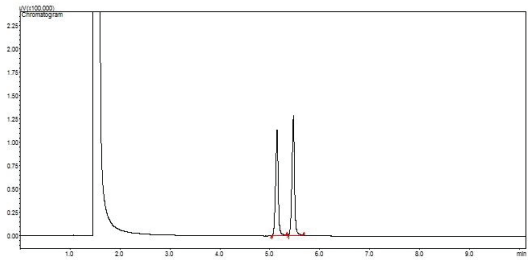

(d)

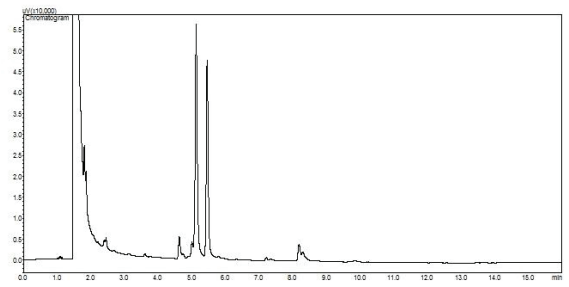

(e)

Figure 6. GC chromatograms of LDC and PLC mixture degradation condition (liquid state). (a) Basic state, (b) acidic state, (c) neutral state, (d) oxidative state, and (e) photolytic state.

photolytic state are shown in Figure 6. Hence, it proves that the method is stable for force degradation study. The results are shown in Table 1.

\section{CONCLUSION}

The proposed green GC technique has been developed for the simultaneous analysis of LDC and PLC in their topical formulation. The technique was validated according to ICH guidelines. The technique was found to be linear, precise, and accurate, which demonstrates the reliability of the proposed technique. The developed method proves superiority over other reported methods due to the minimum use of solvents. Thus, the developed green GC technique can be utilized for routine quality control examination of LDC and PLC in their topical cream formulation.

\section{ACKNOWLEDGMENTS}

The authors are highly obliged to the Principal, JSS College of Pharmacy, JSS Academy of Higher Education and Research, Mysuru, for providing the necessary facilities for the study.

\section{CONFLICT OF INTEREST}

None.

\section{REFERENCES}

Atila A, Kadioglu Y. Determination of prilocaine $\mathrm{HCl}$ in pharmaceutical preparation and human plasma with spectrophotometery. Int J Pharm Sci Res, 2012; 3(4):1018.

Baniceru M, Croitoru O, Popescu SM. Determination of some local anesthetics in human serum by gas chromatography with solid-phase extraction. J Pharm Biomed Anal, 2004; 35(3):593-8. 
Bannimath GV, Purohit MN, Pujar GV. Determination of Ketoprofen in tablet dosage form by gas liquid chromatography. World $\mathrm{J}$ Chem, 2010; 5(1):67-70.

Chandan RS, Gurupadayya BM, Indupriya M. Quantitative determination of lamotrigine by gas chromatography using Ethyl chloroformate as a derivatizing reagent in pure and Pharmaceutical preparation. Indo Am J Pharm, 2013; 3(10):8284-9.

Culea M, Palibroda N, Moldovan Z, Abraham AD, Frangopol PT. Gas chromatographic study of some local anesthetics. Chromatographia, 1989; 28(1-2):24-6.

Dal Bo L, Mazzucchelli P, Marzo A. Highly sensitive bioassay of lidocaine in human plasma by high-performance liquid chromatographytandem mass spectrometry. J Chromatogr A, 1999; 854(1-2):3-11.

Fijałek Z, Baczyński E, Piwońska A, Warowna-Grześkiewicz M. Determination of local anaesthetics and their impurities in pharmaceutical preparations using HPLC method with amperometric detection. J Pharm Biomed Anal, 2005; 37(5):913-8.

ICH I. Q2 (R1): Validation of analytical procedures: text and methodology. International Conference on Harmonization, Geneva, Switzerland, 2005.

Indupriya M, Chandan RS, Gurupadayya BM, Sowjanya K. Quantitative determination of levetiracetam by gas chromatography using ethyl chloroformate as a derivatizing reagent in pure and pharmaceutical preparation. Int J Pharm Tech, 2011; 3(1):1694-701.

Kadioglu Y, Atila A. Development and validation of gas chromatography-mass spectroscopy method for determination of prilocaine $\mathrm{HCl}$ in human plasma using internal standard methodology. Biomed Chromatogr, 2007; 21(10):1077-82.

Kadioglu Y, Atila A. GC determination of prilocaine $\mathrm{HCl}$ in human plasma: analytical application to real samples. Chromatographia, 2008; 67(9-10):755-9.

Karthikkumar B, Thiruvengadarajan VS, Begum NT. Analytical method development and validation of lidocaine in ointment Formulation by UV spectrophotometric method. Int J Pharm Sci, 2012; 4(2):610-4.

Keenaghan JB. The determination of lidocaine and prilocaine in whole blood by gas chromatography. Anaesthesiology, 1968; 29(1):110-2.

Klein J, Fernandes D, Gazarian M, Kent G, Koren G. Simultaneous determination of lidocaine, prilocaine and the prilocaine metabolite o-toluidine in plasma by high-performance liquid chromatography. J Chromatogr B Biomed Sci Appl, 1994; 655(1):83-8.

Koehler A, Oertel R, Kirch W. Simultaneous determination of bupivacaine, mepivacain, prilocaine and ropivacain in human serum by liquid chromatography-tandem mass spectrometry. J Chromatogr A, 2005; 1088(1-2):126-30

Levine B, Blanke R, Valentour J. Gas chromatographic analysis of lidocaine in blood and tissues. J Anal Toxicol, 1983; 7(3):123-4.

Liawruangrath S, Liawruangrath B, Pibool P. Simultaneous determination of tolperisone and lidocaine by high performance liquid chromatography. J Pharm Biomed, 2001; 26(5-6):865-72.

Malenovic A, Medenica M, Ivanovic D, Jancic B, Markovic S. Development and validation of RP-HPLC method for cetrimonium bromide and lidocaine determination. II Farmaco, 2005; 60(2):157-61.

Mohammad MA. LC determination of lidocaine and prilocaine containing potential risky impurities and application to pharmaceuticals. Chromatographia, 2009; 70(3-4):563-68.

Narendra MG, Shailesh JW. Development and validation of HPLC method for simultaneous determination of lidocaine and prilocaine in topical formulation. Asian J Pharm Clin Res, 2017; 10(10): $179-82$.

Pendela M, Kahsay G, Baekeland I, Van Schepdael A, Adams E. Simultaneous determination of lidocaine hydrochloride, hydrocortisone and nystatin in a pharmaceutical preparation by RP-LC. J Pharm Biomed, 2011; 56(3):641-44.

Plenis A, Konieczna L, Miękus N, Baczek T. Development of the HPLC method for simultaneous determination of lidocaine hydrochloride and tribenoside along with their impurities supported by the QSRR approach. Chromatographia, 2013; 76(5-6):255-65.

Powell MF, Hydrochloride LL. Analytical profiles of drug substances. Academic Press, New York, NY, Vol. 15, pp 761-79, 1986.

Reynolds F, Beckett AH. The determination of bupivacaine, lignocaine and mepivacaine in human blood. J Pharm Pharmacol, 1968; 20(9):704-08.

Ricci Júnior E, Bentley MV, Marchetti JM. HPLC assay of lidocaine $\mathrm{n}$ in vitro dissolution test of the Poloxamer 407 gels. Braz J Pharm Sci, 2002; 38(1):107-11.

Rishiraj B, Epstein JB, Fine D, Nabi S, Wade NK. Permanent vision loss in one eye following administration of local anesthesia for a dental extraction. Int J Pharm Sci Res, 2005; 34(2):220-3.

Rizk MS, Issa YM, Shoukry AF, Atia EM. Spectrophotometric determination of lignocaine in pure form and in pharmaceutical preparations. Anal Lett, 1997; 30(15):2743-53.

Siluveru M, Stewart JT. Stereo selective determination of R-(-)and $\mathrm{S}-(+)$-prilocaine in human serum by capillary electrophoresis using a derivatized cyclodextrin and ultraviolet detection. J Chromatogr B Biomed Sci Appl, 1997; 693(1):205-10.

Storms ML, Stewart JT. Stability-indicating HPLC assays for the determination of prilocaine and procaine drug combinations. J Pharm Biomed Anal, 2002; 30(1):49-58.

Ter Weijden E, Van den Broek MP, Ververs FF. Easy and fast LC-MS/MS determination of lidocaine and MEGX in plasma for therapeutic drug monitoring in neonates with seizures. J Chromatogr B, 2012; 881:111-14

Thejaswini JC, Gurupadayya BM, Raja P. Gas chromatographic determination of pregabalin in human plasma using ethyl chloroformate derivatizing reagent. J Pharm Res, 2012; 5(6):3112-5.

Vijayakumar KB, Bannimath G, Koganti VS, Iyer VB. Gas chromatographic method for analysis $\beta$-Asarone in rhizome extracts of Acorus calamus and their microbiological evaluation. Pharm Methods, 2016; 7(2):121-6.

Warren RE, Van de Mark TB, Weinberg S. Methemoglobinemia induced by high doses of prilocaine. Oral Surg Oral Med Oral Pathol, 1974; 37(6):866-71.

Watanabe T, Namera A, Yashiki M, Iwasaki Y, Kojima T. Simple analysis of local anaesthetics in human blood using headspace solid-phase micro extraction and gas chromatography-mass spectrometry-electron impact ionization selected ion monitoring. J Chromatogr B Biomed Sci Appl, 1998; 709(2):225-32.

Wiberg K, Jacobsson SP. Parallel factor analysis of HPLC-DAD data for binary mixtures of lidocaine and prilocaine with different levels of chromatographic separation. Anal Chim Acta, 2004; 514(2):203-09.

Yang Y, Zhang W, Ye L. Simultaneous determination of prilocaine and lidocaine in transdermal receiving fluid using gas chromatographymass spectrometry. Chin J Chromatogr, 2009; 27(1):74-7.

Zylber-Katz E, Granit L, Levy M. Gas-liquid chromatographic determination of bupivacaine and lidocaine in plasma. Clin Chem, 1978, 24(9):1573-5.

How to cite this article:

Marakkarakath HC, Bannimath G, Raikar PP. Simultaneous estimation of lidocaine and prilocaine in topical cream by green gas chromatography. J Appl Pharm Sci, 2019; 9(03):066-072. 